\title{
KEY INDICATORS OF EFFICIENCY OF INNOVATIVE ACTIVITY IN REGIONAL COMPANIES OF TOURISM INDUSTRY
}

\author{
Oksana Podvalnaya ${ }^{1}$ \\ ${ }^{1}$ Ph.D. (Economics), Associate Professor, Associate Professor, Agricultural Management Department, Vinnitsa \\ National Agrarian University, Vinnitsa, Ukraine, e-mail: np070101@gmail.com, ORCID: https://orcid.org/0000-0001- \\ 6767-7882
}

Citation:

Podvalnaya, O. (2020). Key indicators of efficiency of innovative activity in regional companies of tourism industry. Economics, Finance and Management Review, (2), 29-34. https://doi.org/10.36690/2674-52082020-2-29

Received: April 30, 2020

Approved: May 28, 2020

Published: June 05, 2020

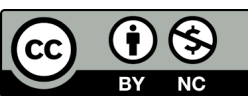

This article is an open access article distributed under the terms and conditions of the Creative Commons Attribution (CC BY-NC 4.0) license

OPEN ACcess
Abstract. The article explores the main methods and approaches to assessing the effectiveness of innovation in companies in the tourism industry. The purpose of the study is to analyze the main indicators of innovation efficiency in regional companies operating in the tourism sector. The theoretical and methodological basis of scientific work are general scientific principles, methods, provisions, highlighted in the works of scientists involved in solving problems of innovative development of tourism. The analysis of economic and organizational-legal mechanisms, the acquisition of which leads to an increase in the management of innovation in tourism. It was determined that within the framework of the acquisition of these mechanisms, the main task is to combine the efforts of all interested parties to ensure the synergistic effect of various actors. A number of specific indicators are presented: the integrated effect of all new products and technologies; profitability index for each new product; rate of return on tourism activities; payback period of the resources involved; with the help of which the effectiveness of the results of innovation in the tourism sector is assessed. A basic set of parameters is proposed for a system of indicators for assessing innovation in the tourism industry in the region.

Keywords: tourism industry, innovation, efficiency, economy, region.

JEL Classification: 031 L83

Formulas: 0; fig.: 0; tabl.: 1; bibl.: 5

Introduction. To assess the effectiveness of innovation, various approaches and methods are applied that need to be adapted to the characteristics of the tourism industry in the regions of Ukraine. As a result of a comparative analysis of various methods and tools, we came to the conclusion that the most applicable tool for describing efficiency is the integration of economic and legal mechanisms to improve the effectiveness of managing the results of innovation in the tourism industry. In modern conditions, the analysis of effectiveness is carried out not only regularly, but also comprehensively. This means that in the process of performance analysis, additional sources of information play a very important role, which make it possible to summarize information not only about the company's activities, but also about the regional industry market.

Literature review. Innovative development of enterprises, types of economic activity and territorial systems is the subject of research of many scientists. In particular, many Ukrainian studies (L. Gorbach, O. Davydova, V. Zaitseva, I. Kalganova, Yu. Konoval, Z. Peresunko, A. Tretyak, P. Khariv, L SzymanowskaDianich, etc.) and foreign (P. Drucker, B. Santo, J. Schumpeter, etc.) scientists.

Despite the fact that the problems of innovative development of the economy and its individual spheres in general are quite thoroughly studied, some problems need more detailed analysis, in particular on the formation of sufficient theoretical and methodological basis for research and development of organizational and economic mechanisms to stimulate innovative development of certain promising 
economic activities. First of all, this applies to the service sector, in particular tourism, where innovation is not only dynamic, but also specific features of development, implementation and spatial organization.

Aims. The purpose of the study is to analyze the main indicators of innovation efficiency in regional companies operating in the tourism sector.

Methods. The theoretical and methodological basis of scientific work are general scientific principles, methods, provisions, highlighted in the works of scientists involved in solving problems of innovative development of tourism.

Results. From the point of view of increasing the efficiency of innovation management in tourism industry companies, the largest contribution can be made by the acquisition of economic and organizational-legal mechanisms presented in table 1 .

\section{Table 1. Economic and organizational-legal mechanisms, the acquisition of which leads to an increase in the effectiveness of innovation management}

\begin{tabular}{|l|l|}
\hline \multicolumn{1}{|c|}{ The name of the mechanism } & \multicolumn{1}{c|}{$\begin{array}{c}\text { Institutions attracted by the tourism industry } \\
\text { company to implement the mechanism }\end{array}$} \\
\hline Share in innovative projects & Industry market \\
\hline Outsourcing & Innovative enterprises \\
\hline Venture financing & Investors \\
\hline Commercialization of new technologies & Industry market \\
\hline Contrast-competitive mechanism & Industry market \\
\hline Project management & Partners, temporary units \\
\hline Valuation Activities & Consulting companies \\
\hline Patent research & Innovative enterprises \\
\hline Legal protection of the results of innovation & The state represented by executive authorities \\
\hline $\begin{array}{l}\text { Distribution of property rights on the results } \\
\text { of innovation }\end{array}$ & Partners, customers, industry market \\
\hline Strategic Product Range Planning & Potential listeners, industry market \\
\hline Insurance & Financial market \\
\hline Technology audit & Investors \\
\hline Technology exchange & Industry market \\
\hline Financial leasing & Financial market \\
\hline Franchising & Financial market \\
\hline
\end{tabular}

Source: developed by authour

As you can see, the initiative and the main role in the implementation of various economic or legal mechanisms belongs to various stakeholders of the innovation process. Therefore, in the framework of the acquisition of these mechanisms, the main task is to combine the efforts of all interested parties to ensure the synergistic effect of various actors:

- the industry market, which acts as the initiator of the development of innovations and carries out their resource provision at the expense of development budgets, as well as stimulating the development of tourism companies in the region;

- investors acting as the main source of financial resources necessary to create competitive tourism products, new programs and logistics systems for the tourism process in the region based on the results of innovation; 
- higher education institutions, which are the scientific, technical and industrialtechnological base, ensuring the transformation of financial (investment) resources into innovations, and then into intellectual property and other products delivered to the relevant markets.

In accordance with the interests of these groups, intellectual capital management begins to play a special role in the process of managing innovation activity as a source of new knowledge and competencies.

As the studies showed, formally, this task can be reduced to assessing the effectiveness of each of the elements of the link "industry market - investor - tourism industry company". The solution to this problem is relevant because the traditional combination: "the industry market is a tourism industry company" is standard and the organizational and economic mechanism of its functioning is quite developed. It is advisable to proceed from the fact that the inclusion of an additional component in this bundle - investors providing financing for the transformation of the created results of innovative activity into a tourism product, the implementation of which on the market will create an additional economic effect and lead to an increase in the functioning efficiency of each subject of this triad, in principle, recognize methodologically justified.

When researching the functioning of the "industry market - investor - tourism industry company" combination, it is necessary to take into account not only the diverse nature of the entities included in the combination, which determine the various ways to achieve their goals, but also their interests that do not coincide initially. Using the basic principles of game theory, it is proposed to solve this problem in three stages:

- solving the game of the traditional bundle: "industry market - a company in the tourism industry";

- solving a cooperative game in which, under equal conditions, a third player, an investor, is added for players such as the industry market and the tourism industry company;

- assessment of the increment in the effectiveness of each player of the "industry market - tourism industry company" combination and, on this basis, formulating conclusions on the advisability of including an investor as a third player.

Ultimately, this will allow us to determine the structure of the main mechanisms providing a positive increment in the functioning efficiency of each of the elements of the link "industry market - investor - tourism industry company".

The effectiveness of new products and technologies, as a rule, is evaluated on the basis of their actual ability to save certain resources: labor, time, inventories and money - based on the unit of expected beneficial effect created by a new product or technology. The term "new product effectiveness" itself covers the entire gamut of problems of analyzing the results of innovation in a variety of aspects: the economic efficiency of the results; scientific and technical level of work; product social performance; environmental performance after the introduction of the product.

Recently, opinions have appeared that the integral effect of innovative activity contains the three most important components: socio-economic, scientific, technical 
and environmental. These components have a certain unity, and envelop the mutual influence on each other. This means that the overall result obtained from the introduction and promotion of new products and technologies can be calculated as a combination of economic, social, technical or purely environmental results [1].

In a planned economy, when centralized decision-making methods prevailed throughout the country, the corresponding centralized, common for all economic entities approach to assessing the effectiveness of innovative activities also prevailed. This approach was based on the principle that everything that is beneficial for the state should be beneficial for the business entity [4].

This principle provided for a common global criterion for the effectiveness of innovation activity for all economic entities - the economic effect obtained at all stages and stages of creating an innovation, that is, from research and development to the introduction of a new product.

If we follow the classical canons of economic theory, according to which the activity of economic entities is based on freedom of choice, and the state's function is to regulate the interaction of various economic entities, we can conclude that it is advisable to distinguish at least two types of performance criteria [4].

Firstly, these are individual criteria for the effectiveness of business entities that, under the influence of the external environment, strive to obtain the maximum effect and ensure long-term sustainability.

Secondly, it is a global criterion for the effectiveness of the entire economic system, on which the state economic policy is based, aimed at ensuring the dynamic development of society as a whole.

Recognition of the presence of these heterogeneous and, at first glance, conflicting groups of criteria requires the development and adaptation of various methods for assessing the effectiveness of innovative activities, which, in accordance with the accepted classification, can be not only macro- but also microeconomic. In modern conditions of intensive development of the tourism industry, the introduction of information technology, the development of delivery vehicles, the problem of economic justification of the priorities of innovation is becoming particularly relevant. Such problems arise both at the level of individual companies in the tourism industry in the region, and at the top level of managing the national economy when allocating various resources to ensure environmental, social and other state programs [5].

An important distinguishing feature of companies in the tourism industry should be considered differences in the strategic goals that they pursue in the implementation of innovative activities. So, large tour operators, called to carry out the formation and general regulation of tourist flows, should obviously proceed from the strategic goals of the development of a destination or a whole destination. There is no significant difference with the tasks and goals that the relevant government bodies had previously solved. The main difference is the ways to achieve your goals [2].

If in the conditions of a command-administrative economy the plan was the main way of coordinating the directions of innovation activity, then in market conditions key players form a business environment for doing business for small 
companies in the region, creating conditions and incentives for the economic growth of the tourism industry as a whole. Differences in the tasks that companies of the tourism industry of various sizes solve can manifest themselves not only in the difference in the criteria used to make decisions on the directions and scope of innovation, but also in methods for assessing the effectiveness of the results of this activity. In particular, the evaluation of the effectiveness of the results of innovation can be carried out using the following indicators:

1) the integrated effect of all new products and technologies;

2) profitability index for each new product;

3 ) the rate of return on tourism activities;

4) the payback period of the resources involved.

The main indicators for comparing new products and technologies with each other and choosing the highest priority for implementation are the coefficients of the integral effect.

The company of the tourism industry can interact with other actors of the industry market on a territorial scale either as a source of innovative ideas, or as sources of resources for innovative activities, or as an internal consultant for testing new products and technologies. In all of the listed participation options, the tourism industry company gains access to additional resources for the development of the innovation management system, as it can use the resources of other tourism industry companies as an experimental base.

Various units carry out their activities in accordance with the format and nature of the tasks facing them, and regardless of the nature of the unit, innovative activities can be carried out in various formats:

- regular participation in innovation (technology marketing, testing and customer surveys, commercialization);

- periodic or project participation in innovative activities (brainstorming, examination of products and technologies);

- one-time activities (self-testing, testing).

Discussion. That is, the format of participation and the degree of involvement make it possible to formulate a list and values of target indicators. Thus, when developing a system of key performance indicators, in our opinion, it is advisable to take into account a number of features that arise in the process of solving a specific problem in the tree of goals of the innovation strategy: the format of participation; work performed; basic authority; core competencies; responsibility for the result. The basic set of parameters for a system of indicators for assessing innovation in the tourism industry can be as follows:

1. Product development indicators: the number of proposed and implemented changes in the development of a product or technology for the period; fact and plan for the deadline for introducing new destinations in the product portfolio; fact and plan for the introduction of new products or technologies; the total number of new products for the period; number of products introduced on time; the number of proposals for the development of destinations completed in the high season; total 
number of product development proposals; fact and plan for the schedule for introducing modernized products into the product portfolio;

2. Technology development indicators: the number of proposals for improving business processes; the number of implemented proposals for optimizing business processes; fact and plan for the implementation of business process optimization proposals; the number of adjustments to the technology modernization plan; the number of identified technologies for the period for destinations and products for the period; the total number of new technologies for leading products; number of updated technologies for leading products for the period;

3. Infrastructure development indicators: fact and plan for the commissioning of new infrastructure; fact and plan for the introduction of new sales and promotion systems (by product); the proportion of termination lines and infrastructure facilities introduced on time; fact and plan for the development of new technologies for the operation of infrastructure facilities; the share of projects for the modernization of facilities completed late with respect to the commissioning schedule;

4. Indicators of marketing and risk management: fact and plan to mitigate risks; tourist satisfaction with a new product; the proportion of proposals for the development of promotion technologies implemented according to plan-; the share of business process optimization projects completed on time.

Conclusions. Thus, the use of the totality of indicators allows not only to improve the quality of planning of the main works within the framework of innovation, to distribute responsibility among key tasks, but also to increase the degree of implementation of all activities of the innovation strategy. This leads to increased competitiveness of the tourism industry company in the regions, increases the effectiveness of innovation and reduces the cost of commercializing the results of innovation.

\section{References:}

1. Davydova, O. (2015), "Features of application of innovations in development of tourist branch of Ukraine”, Bulletin of Taras Shevchenko National University of Kyiv, №7(172), pp. 65-69.

2. Golod, A.P. (2018), Model of socio-ecological and economic security of regional tourist systems" Conceptual foundations of socio-environmental and economic security, monograph, Lutsk, pp. 272-285.

3. Zaitseva, V.M. (2015), The use of innovative technologies in tourism, monograph, Zaporozhye, $143 \mathrm{p}$.

4. Krupsky, A.P. (2015), "The conceptual framework for the management of innovative activities of tourism enterprises”, Bulletin of the Dnepropetrovsk university. Innovation management series, №4, pp. 64-71.

5. Novikov, V.S. (2010), Innovation in tourism, Moscow, 208 p. 